\title{
$\operatorname{coN} F-910575-1$
}

SA1097.0217C SAND--97-0219C

\section{Ion Energy Distribution Functions in Inductively Coupled RF Discharges in mixtures of Chlorine and Boron Trichloride}

J. R. Woodworth, C.A. Nichols, Laser, Optics, and Remote Sensing Department,
National Laboratories*, Albuquerque, NM, 87185-1423
T. W. Hamilton, Applied Physics International, Inc. Albuquerque, NM 87110

Abstract

Weare using a gridded energy analyzer to measure positive ion energy distributions and fluxes at the grounded electrode of high-density inductively-coupled if discharges. In this paper, we present details of ion energies and fluxes in discharges containing mixutres of chlorine and boron trichloride

\section{Introduction}

Plasma discharges involving mixtures of chlorine and boron trichloride are widely used to etch metals in the production of very-large-scale-integrated cirucits. ${ }^{1,2}$ Energetic ions play a critical role in this process, influencing the etch rates, etch profiles, and selectivity to different materials. In addition, energetic ions can contribute to device damage in the circuits being processed. Inductively coupled or "transformer coupled" discharges are becoming increasingly popular for semiconductor processing due to the high plasma densities and low pressures achievable, the relative independence of ion flux and ion energy they provide, and the relative simplicity of the apparatus. In order to better understand these inductively coupled discharges, several groups are developing computational models ${ }^{3-8}$ and making detailed measurements of discharge parameters. ${ }^{9-13}$ As part of this effort, in this paper we report ion fluxes and ion energy distributions made with a gridded energy analyzer in inductively-coupled if discharges in mixtures of chlorine and boron trichloride.

\section{Apparatus}

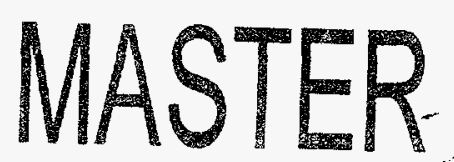

Our experiments were carried out in a Gaseous Electronics Conference Reference Cell (GEC Ref. Cell) ${ }^{14,15}$ which had been modified to produce inductively-coupled discharges. ${ }^{16}$ A schematic of our cell, including the five-turn planar induction coil at the the top of the cell and the ion analyzer at the bottom of the cell is shown in Fig. 1. To excite the plasma, if energy at $13.56 \mathrm{MHz}$ was coupled from the if coil, through a quartz window, to the discharge region. The stainless steel lower electrode was grounded for these experiments. The pinholes were laser-drilled in thin stainless steel discs which were glued into the center of the electrode with conductive epoxy.

The ion analyzer used in these experiments was a gridded energy analyzer. This analyzer : has been described in detail previously ${ }^{11,12}$ and only a brief summary of its operation will 


\section{DISCLAIMER}

This report was prepared as an account of work sponsored by an agency of the linited States Government. Neither the United States Government nor any agency thereof, nor any of their employees, make any warranty, express or implied, or assumes any legal liability or responsibility for the accuracy, completeness, or usefulness of any information, apparatus, product, or process disclosed, or represents that its use would not infringe privately owned rights. Reference herein to any specific commercial product, process, or service by trade name, trademark, manufacturer, or otherwise does not necessarily constitute or imply its endorsement, recommendation, or favoring by the United States Government or any agency thereof. The views and opinions of authors expressed herein do not necessarily state or reflect those of the United States Government or any agency thereof. 


\section{DISCLAMMER}

Portions of this document may be illegible in electronic image products. Images are produced from the best available original document. 
be given here. A schematic of the ion analyzer is shown in figure 2. The detector contains three screen grids and a series of annular current-collecting electrodes. The three grids and the electrodes all form sections of concentric hemispheres which are centered on the $10 \mu \mathrm{m}$ diameter pinhole. Forming the grids and electrodes into sections of concentric hemispheres allowed the detector to accurately measure the ion energies regardless of the angle of the ion's trajectory when it passed through the pinhole. This hemispherical design and the annular electrodes also allowed the detector to measure ion angular distributions, but this capability was not used in these experiments. The first grid (nearest the pinhole) was grounded and the third grid was held at a negative potential to suppress secondary electron emission from the electrodes. The voltage on the second grid was varied from 0 to +40 volts to sweep out the ion energy distribution function. Only ions with energies greater than the voltage on the second grid were passed by the grids and detected by the collecting electrodes. Thus, the ion energy spectrum was the derivative of the signal at the collecting electrodes as a function of the voltage on the second grid. In these experiments, all of the electrodes were tied together, and the ion currents were measured with a picoammmeter. Once the pinhole size and the screen transmissions were collected for, the ion signals could also be used to determine the ion flux to the lower electrode.

\section{Results and Discussion}

Figure 3 shows ion fluxes versus pressure for a number of $\mathrm{Cl}_{2} / \mathrm{BCl}_{3}$ mixtures. Power to the matching network feeding the if coil was $200 \mathrm{~W}$ for this data. Previous work has shown that approximately $80 \%$ of the power to the matching network is dissipated in the plasma. This figure shows that addition of $\mathrm{BCl}_{3}$ to a $\mathrm{Cl}_{2}$ discharge can decrease the ion flux to the lower electrode by a factor of two to three, depending on the pressure. Note that ion flux in discharges containing $\mathrm{BCl}_{3}$ decreases as pressure increases. This is in contrast to discharges in pure $\mathrm{Cl}_{2}$ in which ion fluxes increased slightly as pressure increased. ${ }^{20}$ Also, the fluxes in pure $\mathrm{BCl}_{3}$ discharges are almost an order of magnitude lower than fluxes in pure Ar discharges under equivalent conditions. ${ }^{11}$

Figure 4 shows ion energy distributions in $3 / 1 \mathrm{Cl}_{2} / \mathrm{BCl}_{3}$ discharges as a function of total pressure. This $3 / 1 \mathrm{Cl}_{2} / \mathrm{BCl}_{3}$ mix ratio is similar to ratios commonly used to etch aluminum contacts. Power to the if matching network was $200 \mathrm{~W}$. At low pressures, the ion energy distributions form a single peak, similar to the distributions seen in most inductively coupled discharges. ${ }^{11,12}$ At higher pressures, however, the distribution splits into a double-peaked distribution even though the lower electrode and pinhole are at ground potential. The most likely source of this splitting appeared to be oscillations in the plasma potential caused by residual capacitive coupling between the if coil and the discharge. We : therefore inserted a Faraday shield just below the window, between the rf coil and the discharge to short out the capacitive coupling and repeated some of the experiments. Figure 5 shows ion energy distributions in pure $\mathrm{BCl}_{3}$ with and without the Faraday shield in place. Since our Faraday shield also appeared to reduce the inductive if power coupled to the discharge, we adjusted the power to obtain equal ion fluxes with and without the shield in place. The double-peaked distribution disappears in figure 5 when the Faraday 
shield is in place, verifying our guess that the splitting was due to residual capacitive coupling between the coil and the discharge.

\section{Summary}

Addition of $\mathrm{BCl}_{3}$ to $\mathrm{Cl}_{2}$ discharges can reduce the flux of positive ions to the lower electrode by a factor of 2 to 3 to levels of $2-4 \mathrm{~mA} / \mathrm{cm}^{2}$. These fluxes are almost an order of magnitude lower than the fluxes seen in pure Ar discharges. At low pressures, the ion energy distributions form a single peak, well separated from zero energy, similar to results in other discharges. At high pressures, the distribution becomes double peaked. This splitting is due to residual capacitive coupling between the $\mathrm{rf}$ coil and the discharge. Further details of the experiment and results will be presented.

\section{References}

* This work was supported by the United States Separtment of Energy under Contract DE-AC04-94AL85000. Sandia is a multiprogram laboratory operated by the Sandia Corporation, a Lockheed Martin Company, for the United States Department of Energy.

1. Dry Etching for VLSI, A. J. vanRoosmalen, J. A. G. Baggerman, and S. J. H. Brader. Plenum Press, New York, 1991.

2. Principles of Plasma Discharges and Materials Processing, Michael A. Lieberman, Allan J. Lichtenberg, John Wiley \& Sons, New York, 1994

3. J. E. Johannes, T. J. Bartel, R. S. Wise, D. J. Economou, paper PS-MoM7: Comparison of Low Pressure $\mathrm{Cl}_{2}$ Plasma Simulations With Experimental Data in an Inductively Coupled Source, 42nd National Symposium of the American Vacuum Society, Minneapolis MN, October 16, 1995

4. R. J. Hoekstra and M. J. Kushner; Predictions of Ion Energy Distributions and Radical Fluxes in Radio Frequency Biased Inductively Coupled Plasma Etching Reactors, Journal of Applied Physics, in press 1996.

5. C. Lee and M. A. Lieberman, J. Vac. Sci. Technol. A (13)2, March/April 1995, p 368

6. E. F. Jaeger, L. A. Berry, J. S. Tolliver and D. B. Batchelor, Physics of Plasmas 2 (6) June 1995, p. 2597

7. E. Meeks and J. W. Shon, J. Vac. Sci. Tech. A 13, (1995), p. 2884

8. E. Gogolides and H. H. Sawin, J. Appl. Phys, 72, (9), 1 Nov, 1992, p. 3971

9. G. A. Hebner, J. Vac. Sci. Technol. A14(4) July/Aug 1996, pps. $2158-2162$

10. G. A. Hebner, J. Appl. Phys, 80 (6), 15 Sept. 1996, pps. 3215 - 3220.

11. J. R. Woodworth, M. E. Riley, D. C. Meister, B. P. Aragon, M: S. Le and H. H Sawin, J. Appl. Pysi. 80 (3), 1 Aug. 1996, pps. 1304 - 1311

12. J. R. Woodworth, M. E. Riley, P. A. Miller, G. A. Hebner and T. W. Hamilton, J. Appl Phys, in press, 1997 
13. J. Liu, G. L. Huppert, and H.H. Sawin, J. Appl. Phys 68 (8) 15 Oct, 1990, pps. $3916-3934$

14. P. J. Hargis, Jr. , et. al Rev. Sci. Instruments, 65, (1994) p. 140

15. J. K. Olthoff and K. E. Greenberg, Journal of Research, National Institute of Standards and Technology 100 (4) July-August, 1995, p. 327

16. P. A. Miller, G. A. Hebner, K. E. Greenberg, P. D. Pochan, and B. P . Aragon, Journal of Research, National Institute of Standards and Technology 100 (4), JulyAugust 1995, p. 427 


\section{Figure Captions:}

Figure 1: Schematic of the GEC Reference Cell used in these experiments. Note that the ion analyzer is located in a separate vacuum system below the grounded lower electrode.

Figure 2: Schematic of ion analyzer. The distance from the pinhole to the collection electrode is $2.3 \mathrm{~cm}$.

Figure 3: Ion fluxes to the lower electrode in $\mathrm{Cl}_{2} \mathrm{BCl}_{3}$ discharge mixtures with $200 \mathrm{~W}$ if input to matching network.

Figure 4: Ion Energy distributions in $3 / 1 \mathrm{Cl}_{2} / \mathrm{BCl}_{3}$ discharge mixtures.

Figure 5: Ion Energy distributions in pure $\mathrm{BCl}_{3}$ with and without Faraday shield in place. 


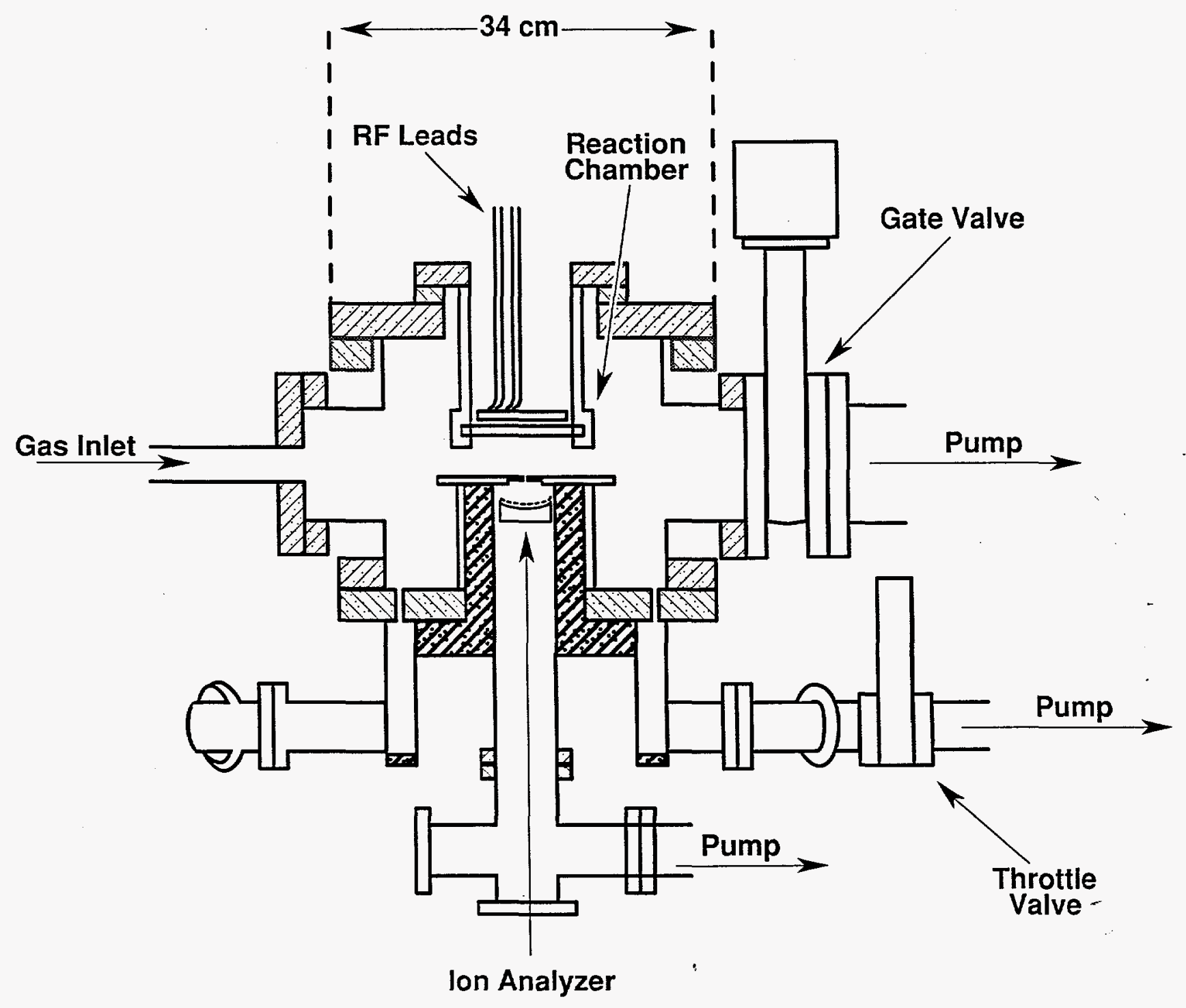




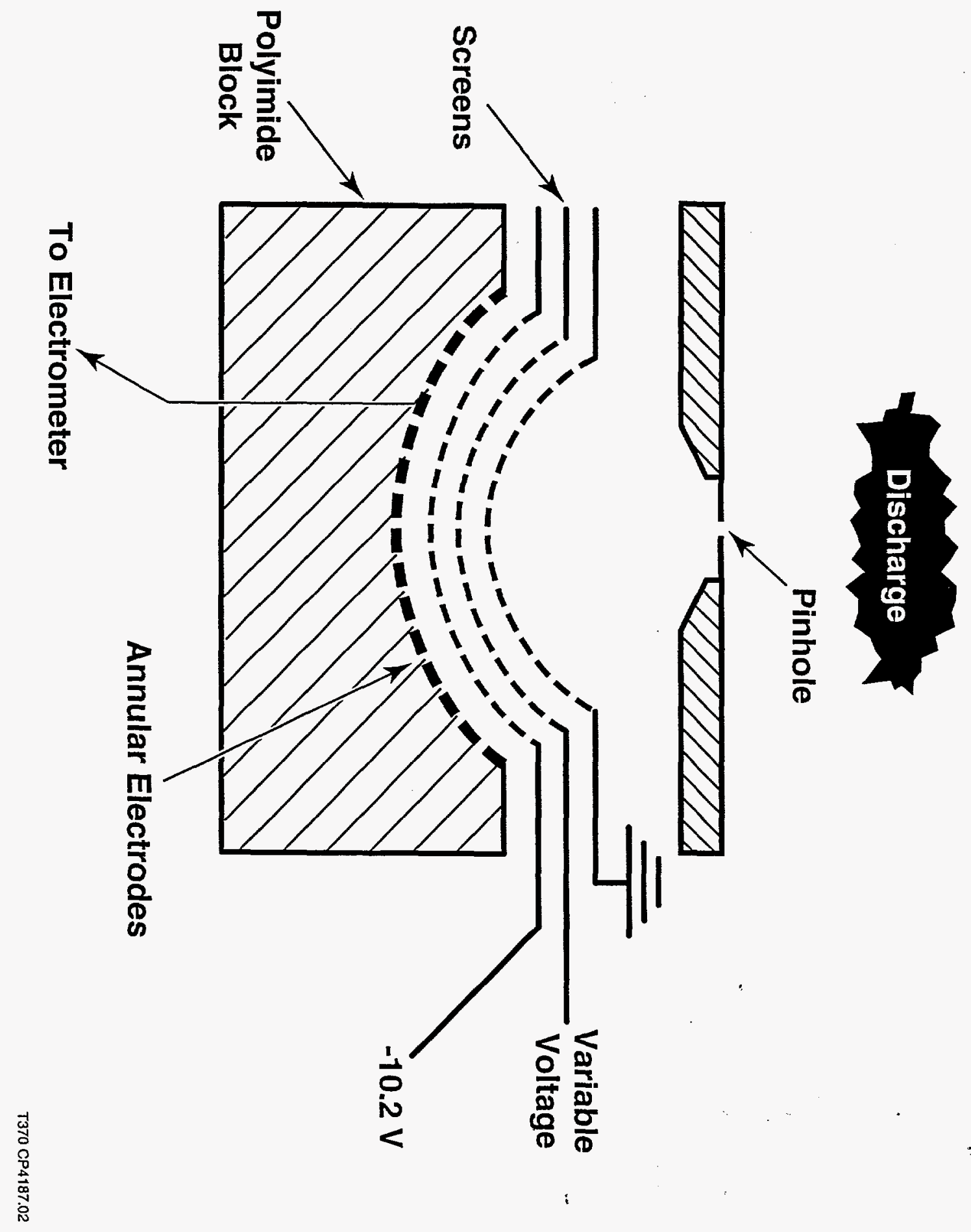




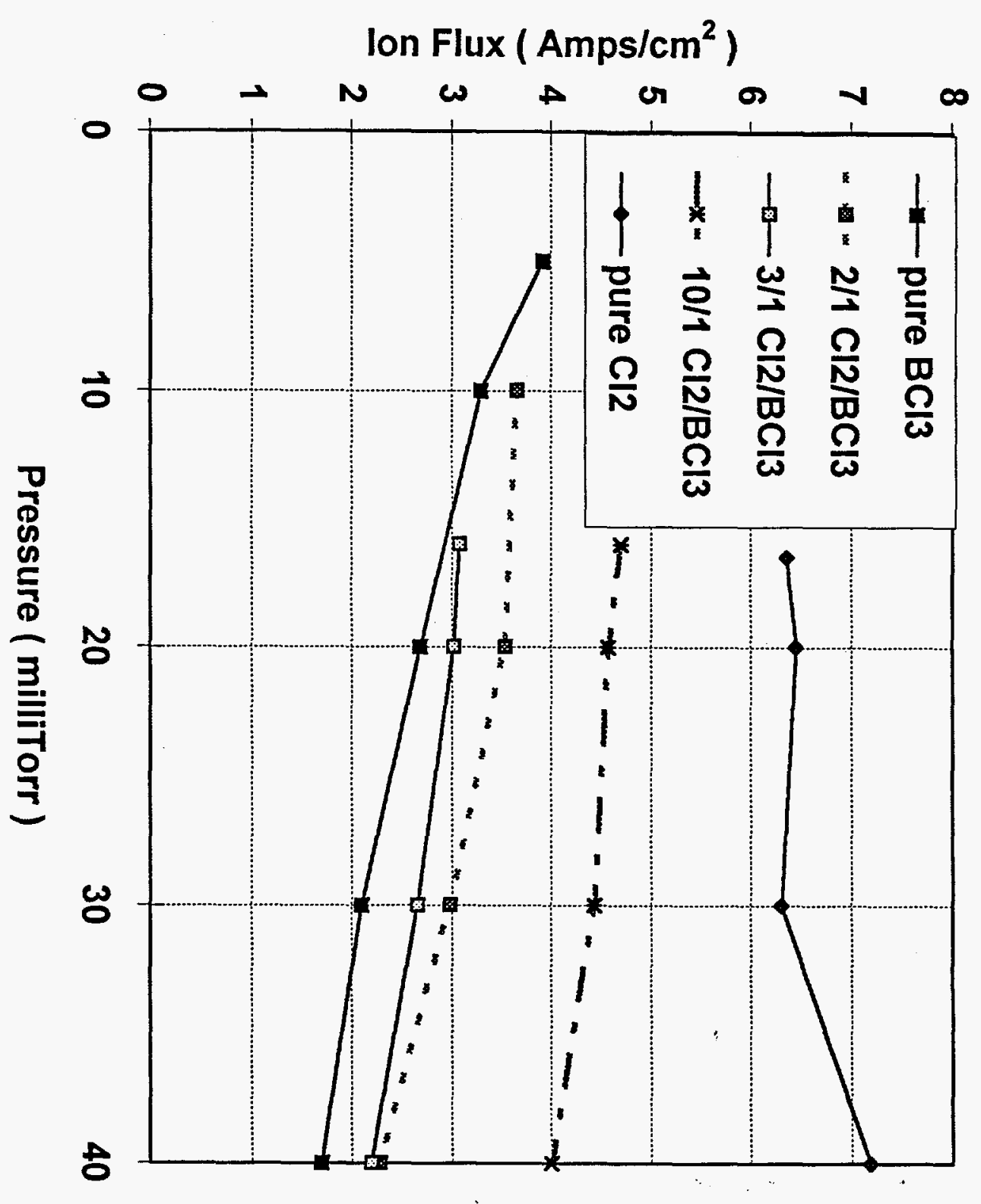

旁 


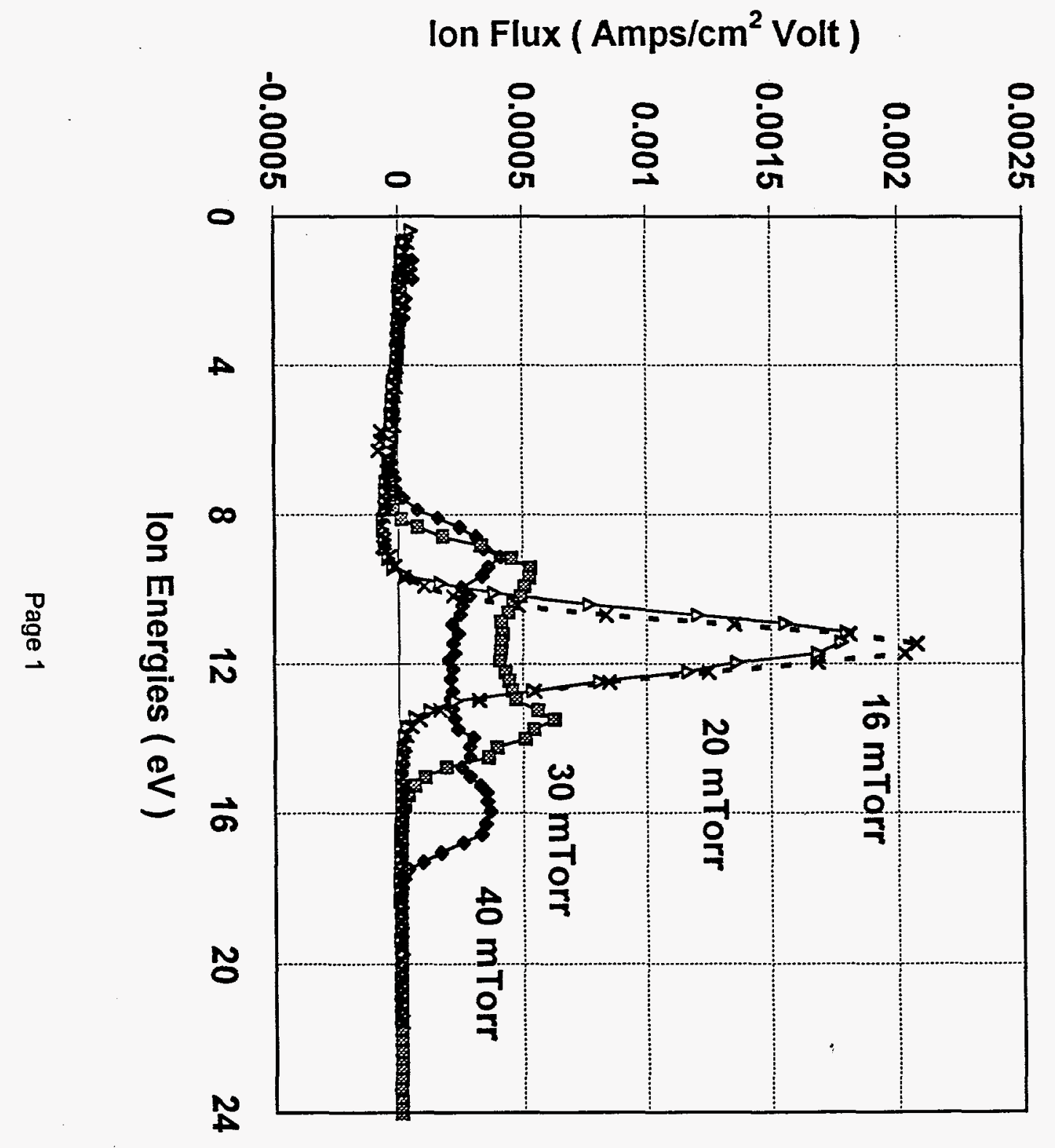

$\frac{\Omega}{\frac{9}{7}}$ 


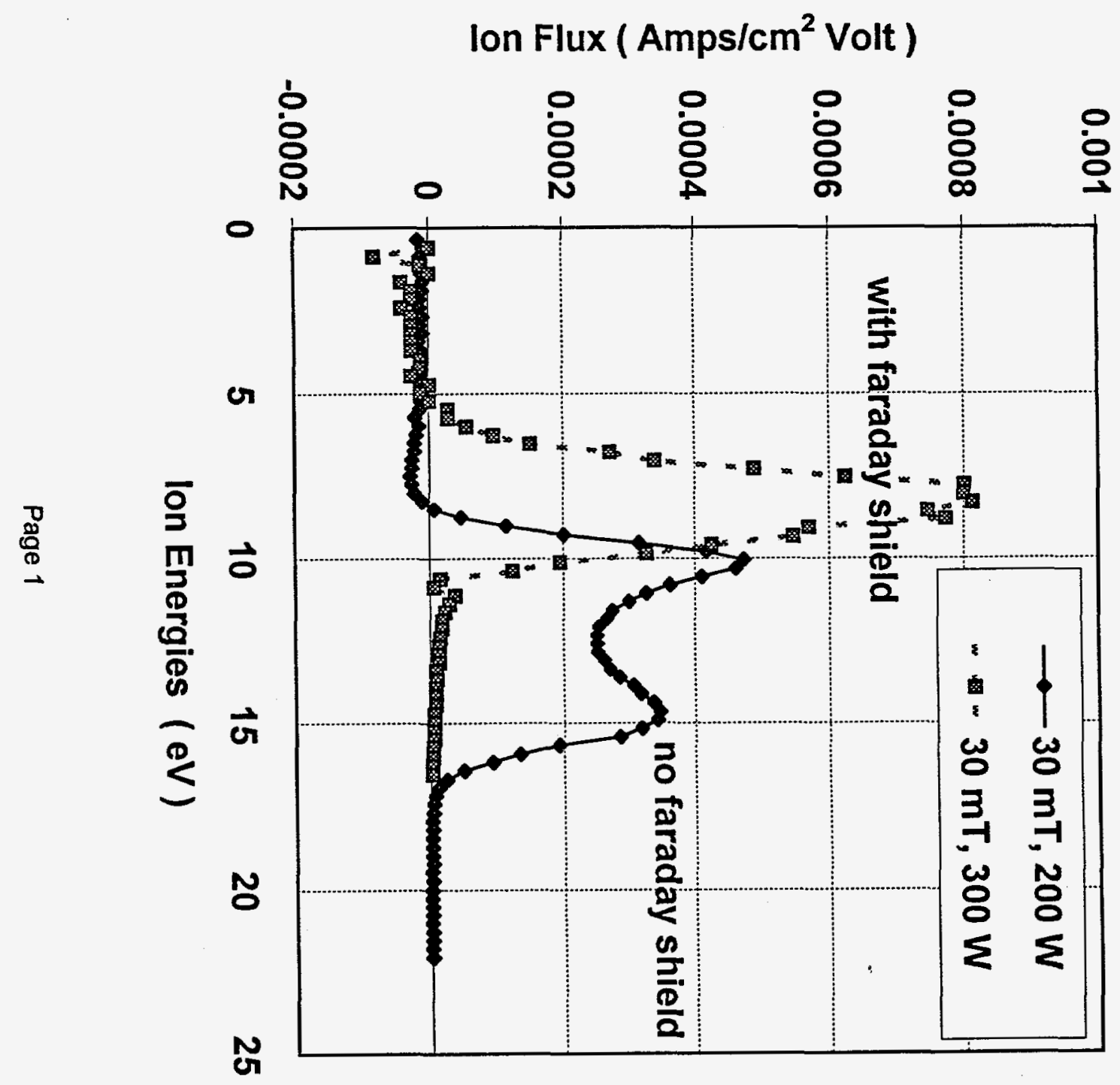

$\frac{\rho}{\frac{\rho}{\omega}}$ 